\title{
Philippe et Pauline de Flers, Robert de Flers. Du théâtre à la Coupole. Biographie, discours de Robert de Flers et hommages rendus
}

\section{Davide Vago}

\section{(2) OpenEdition \\ Journals}

Edizione digitale

URL: http://journals.openedition.org/studifrancesi/584

DOI: $10.4000 /$ studifrancesi.584

ISSN: 2421-5856

\section{Editore}

Rosenberg \& Sellier

\section{Edizione cartacea}

Data di pubblicazione: 1 aprile 2015

Paginazione: 188

ISSN: 0039-2944

\section{Notizia bibliografica digitale}

Davide Vago, "Philippe et Pauline de Flers, Robert de Flers. Du théâtre à la Coupole. Biographie, discours de Robert de Flers et hommages rendus », Studi Francesi [Online], 175 (LIX | I) | 2015, online dal 01 avril 2015, consultato il 18 septembre 2020. URL : http://journals.openedition.org/studifrancesi/584 ; DOI : https://doi.org/10.4000/studifrancesi.584

Questo documento è stato generato automaticamente il 18 settembre 2020.

\section{cc) (†) $\odot$}

Studi Francesi è distribuita con Licenza Creative Commons Attribuzione - Non commerciale - Non opere derivate 4.0 Internazionale. 


\title{
Philippe et Pauline de Flers, Robert de Flers. Du théâtre à la Coupole. Biographie, discours de Robert de Flers et hommages rendus
}

\author{
Davide Vago
}

\section{NOTIZIA}

PHILIPPE ET PAULINE DE FLERS, Robert de Flers. Du théâtre à la Coupole. Biographie, discours de Robert de Flers et hommages rendus, préfaces de Francis VEBER et de Pierre BARILLET, Paris, Champion, 2013 («Champion Essais», 35), pp. 208.

1 Per celebrare il centenario - nel 2013 - de L'Habit Vert, popolarissimo vaudeville scritto da Robert de Flers poco prima della Grande Guerra, il nipote del drammaturgo, Philippe de Flers, aiutato dalla moglie Pauline, ha raccolto una serie di documenti preziosi (testi e fotografie), tratti dagli archivi di famiglia, al fine di restituire un ritratto quanto più possibile autentico del letterato, eroe di guerra e uomo politico conosciuto con il nome di «marquis de Flers». Non è facile riassumere le molteplici e variegate «imprese» di Robert de Flers, che dopo aver scritto, in compagnia del fedele Gaston de Caillavet, L'Habit Vert, satira arguta dell'universo degli académiciens, si vedrà indossare per davvero il celebre abito il 16 giugno 1921, quando sarà accolto tra gli immortali dell'Académie française. Le tre parti, distinte e complementari, di cui si compone il volume, rendono conto della complessa personalità di un intellettuale che ha affrontato anche la guerra con il sorriso.

2 Nella prima parte, «De L'Habit Vert à la Coupole» (pp. 19-80), si ripercorrono sommariamente le grandi tappe della vita di Robert de Flers, dagli studi giuridici fino alle prime pubblicazioni (Vers l'orient, premiato dall'Académie française) che lo indirizzano definitivamente verso la letteratura. Dall'amicizia con Marcel Proust 
all'incontro con Caillavet, con cui il drammaturgo formerà il celebre duo, gli autori si soffermano in particolare sulla nascita e sulla composizione de L'Habit Vert, fornendo numerosi dettagli sulla scenografia, le scelte dei costumi, nonché le reazioni della stampa che accompagnarono il trionfo dell'opera, rappresentata la prima volta nel novembre 1912. Viene altresì narrato l'importante ruolo diplomatico ricoperto da de Flers, nel corso del primo conflitto mondiale, tra Francia e Romania: de Flers riceverà la Legion d'Onore per il valore militare delle sue azioni. In conclusione, vengono descritti i retroscena della sua elezione all'Académie, nonché le successive collaborazioni teatrali con Francis de Croisset, che lavorò a fianco di de Flers dopo la scomparsa di Caillavet.

3 Nella seconda parte del volume, «Discours de Robert de Flers» (pp. 81-142) sono riprodotti per intero il Discours de réception à l'Académie française, che ben dimostra l'intelligenza briosa e non priva di sobrietà del suo autore, nonché il testo, meno facilmente reperibile, pronunciato nell'ottobre del $1921 \mathrm{su}$ La Langue française et la guerre, interessante disamina del genio universale della lingua francese in chiave politica e diplomatica.

4 La terza parte, «Hommages et souvenirs» (pp. 143-198), completa il ritratto dell'uomo, del politico e del letterato, con gli omaggi di Louis Barthou, Édouard Herriot, Francis de Croisset e Henry Bordeaux, da cui emerge la «civilité profonde» (p. 154) dell'esprit che contraddistingue Robert de Flers. Il volume è corredato, in pagine non numerate, da numerose fotografie, riproduzioni di lettere e disegni, frutto delle ricerche d'archivio degli autori. 